\title{
New Record of Thapariella anastomusa (Trematoda: Thapariellidae) Metacercariae in Northern Thailand
}

\author{
Waraporn Phalee ${ }^{1}$, Anawat Phalee ${ }^{2, *}$, Chalobol Wongsawad ${ }^{3,4}$ \\ ${ }^{1}$ Biology Department, Faculty of Science and Technology, Pibulsongkram Rajabhat University, Phitsanulok 65000, Thailand; ${ }^{2}$ Fisheries Program, Faculty \\ of Agriculture and Technology, Nakhon Phanom University, Nakhon Phanom 48000, Thailand; ${ }^{3}$ Biology Department, Faculty of Science, Chiang Mai \\ University, Chiang Mai 50202, Thailand; " Environmental Science Research Center (ESRC), Chiang Mai University, Chiang Mai 50202, Thailand
}

\begin{abstract}
The family Thapariellidae has been reported in only 3 countries since 1990. The objective of this study was to identify Thapariella anastomusa metacercariae in snails in Thailand based on morphological traits using a light (LM) and a scanning electron microscope (SEM). A total of 94 Filopaludina snails were collected and identified as 50 F. martensi martensi and $44 \mathrm{~F}$. doliaris. Metacercariae of $T$. anastomusa were recovered from the snails by the crushing method. The overall prevalence was $22.3 \%$ (21/94), and the mean intensity was 17.0 per snail. The prevalence in $F$. martensi martensi was $24.0 \%(12 / 50)$ and $F$. doliaris $20.5 \%(9 / 44)$ with the mean intensity of 18.8 and 14.8 per snail, respectively. SEM revealed traits such as a concave ventral body and well-developed oral and ventral suckers. This study represents the first report of $T$. anastomusa in South East Asia. While LM and SEM observations provide novel insights into $T$. anastomusa metacercarial morphology and life history, the trematode's life cycle remains unclear. To date, there has been no report of $T$. anastomusa causing infections in humans. However, the snails $F$. martensi martensi and $F$. doliaris carrying the infective stages of $T$. anastomosa are frequently consumed by Thai people. This consumption, particularly uncooked snails, may present a risk of Thapariella infections in humans.
\end{abstract}

Key words: Thapariella anastomusa, Filopaludina, thapariellidae, morphological study

\section{INTRODUCTION}

Thapariella, the only known genus belonging to the Thapariellidae family, was first described by Srivastava in 1953 [1]. Thapariellidae has several features similar to those belonging to the Brachylaimidae family, such as the post-testicular position of the ovary and the vitelline field posterior to the testes. Thapariella also share common morphological features to 2 genera of the family Leucochloridiomorpholidae, and it is likely that they have similar life-cycles and intermediate hosts (Viviparidae) [2]. Whilst there are a number of similarities, the 2 families (Thapariellidae and Brachylaimidae) can be distinguished by the position of the genital pore, ovary, and the presence of a well-developed cirrus sac. There are only 2 known hosts in the Thapariella life-cycle: birds, which host adult Thapariella, and viviparid snails, which are infected by

\footnotetext{
- Received 26 June 2017, revised 11 January 2018, accepted 19 January 2018.

*Corresponding author (anawatt.p@gmail.com)

(C) 2018, Korean Society for Parasitology and Tropical Medicine

This is an Open Access article distributed under the terms of the Creative Commons Attribution Non-Commercial License (http://creativecommons.org/licenses/by-nc/4.0) which permits unrestricted non-commercial use, distribution, and reproduction in any medium, provided the original work is properly cited.
}

the larval stage. The host of Thapariella sporocysts is currently unknown [2]. Although Thapariella has also been reported in India, Democratic Republic of the Congo, and the United States of America, it has not yet been reported from anywhere in Thailand. The aim of this study was to identify and study the morphology of Thapariella anastomusa collected from snails in Thailand using a light microscope (LM) and a scanning electron microscope (SEM).

\section{MATERIALS AND METHODS}

\section{Collection of parasites}

Filopaludina snails were collected from paddy fields in Phitsanulok Province, Thailand. The snails were identified using "The Non-Marine Aquatic Mollusca of Thailand" [3] handbook and examined for T. anastomusa infection using a crushing method. T. anastomusa were then collected and counted under a stereomicroscope. Permission for this study was granted by the owner of the land from which samples were collected. Additionally, the study did not involve any endangered or protected species. 


\section{Morphological study}

The metacercariae of T. anastomusa were compressed and fixed in $5 \%$ formalin, stained with Delafield's hematoxylin, dehydrated in alcohol series, cleared in xylol, and mounted in Permount. All metacercariae were measured and identified based on morphological traits. The prevalence (\%) was calculated according to the percentage of infected snails divided by the total number of snails. Mean intensity was determined by dividing the total number of recovered parasites by the number of infected snails.

\section{Scanning electron microscopy}

T. anastomusa specimens were fixed in $2.5 \%$ glutaraldehyde in a PBS buffer at $4^{\circ} \mathrm{C}$ for $24 \mathrm{hr}$. The specimens were washed several times with the PBS buffer, and post-fixed in 1\% osmium tetroxide in a PBS buffer at $4^{\circ} \mathrm{C}$ for $24 \mathrm{hr}$. They were then washed several times with distilled water, dehydrated using an alcohol series, and dried in a Hitachi HCP-2 critical point drying machine using liquid carbon dioxide as a transitional medium. Finally, specimens were mounted on aluminum stubs and coated with gold using an ion-sputtering apparatus, SPI-Model Sputter Coater, for $4 \mathrm{~min}$. Specimens were examined in a JEOL JSM5400 SEM (JEOL, Tokyo, Japan) operating at 15 kV.

\section{RESULTS}

A total of 94 Filopaludina snails were collected and identified into 2 species. F. martensi martensi and F. doliaris were found in 50 and 44 specimens, respectively (Fig. 1). The prevalence of $T$. anastomusa in both snails was $22.3 \%$ (21/94), and the mean intensity was 17.0 per snail. The prevalence of $T$. anastomusa infections in F. martensi martensi was $24.0 \%$ (12/50), and that in F. doliaris was $20.5 \%(9 / 44)$. The mean intensity of parasites in F. martensi martensi and F. doliaris was 18.8 and 14.8 per snail, respectively.
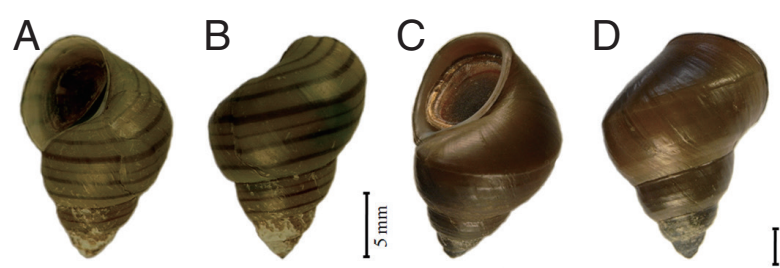

Fig. 1. Photograph of Filopaludina snails collected from paddy fields in Phitsanulok, Thailand. (A, B) Filopaludina doliaris. (C, D) Filopaludina martensi martensi.
Morphological characters of T. anastomusa based on randomly selected samples from 30 snails were measured and described. T. anastomusa had a medium to large linguiform body, 3.0-6.0 $\mathrm{mm} \times 1.7-2.2 \mathrm{~mm}$ that is flat along its entire length (Fig. 2). Oral sucker subterminal, $0.3-0.5 \mathrm{~mm} \times 0.4-0.7 \mathrm{~mm}$; ventral sucker well-developed and muscular, which is located in the middle third of body, 0.6-1.3 $\mathrm{mm} \times 0.7-1.2 \mathrm{~mm}$. Pharynx $0.1-0.2 \mathrm{~mm} \times 0.1-0.3 \mathrm{~mm}$. Esophagus absent. Ceca are simple, long, and extended to the middle of posterior third of body. Interceca testes are slightly diagonal, and almost rounded, 0.2-0.6 $\mathrm{mm} \times 0.2-0.7 \mathrm{~mm}$. Cirrus sac and genital pore are located in the posterior end of body. Ovary is round, 0.1-0.5 $\mathrm{mm} \times 0.1-0.4 \mathrm{~mm}$, smaller than the testes, and located in the post-testicular area. Vitellaria 6 to 7 or 8 branches of follicles located in the hind body. Uterus short, forming several coils in the hind body. Genital atrium present.

The SEM observations revealed a pyriform body shape with a concave ventral body (Fig. 3A), and the tegument of the dorsal body was fold without spines (Fig. 3B). Oral sucker and ventral sucker well-developed. The subterminal oral sucker is located at the anterior part of the body and is scattered with sensory papillae (Fig. 3C). The ventral sucker is located in the anterior 2-thirds of the body and covered by sensory papillae (Fig. 3D). The subterminal excretory pore is located in the hind body and surrounded by sensory papillae (Fig. 3E). Folds and grooves are well developed on all regions of the surface, and have some knobs (Fig. 3F).
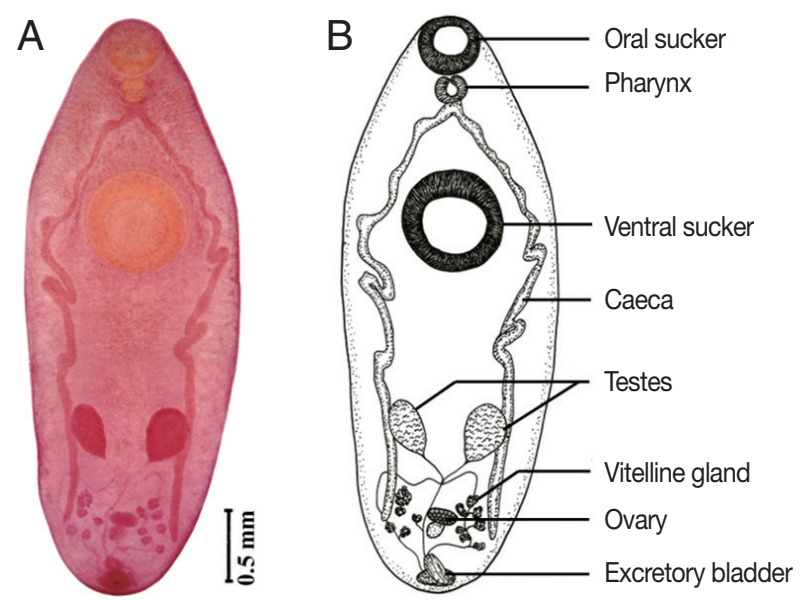

Fig. 2. Photograph of Thapariella anastomusa found in Filopaludina snails showing the internal organization. (A) Light microscopic view of a worm in a permanent slide. (B) Illustration of internal organs. 

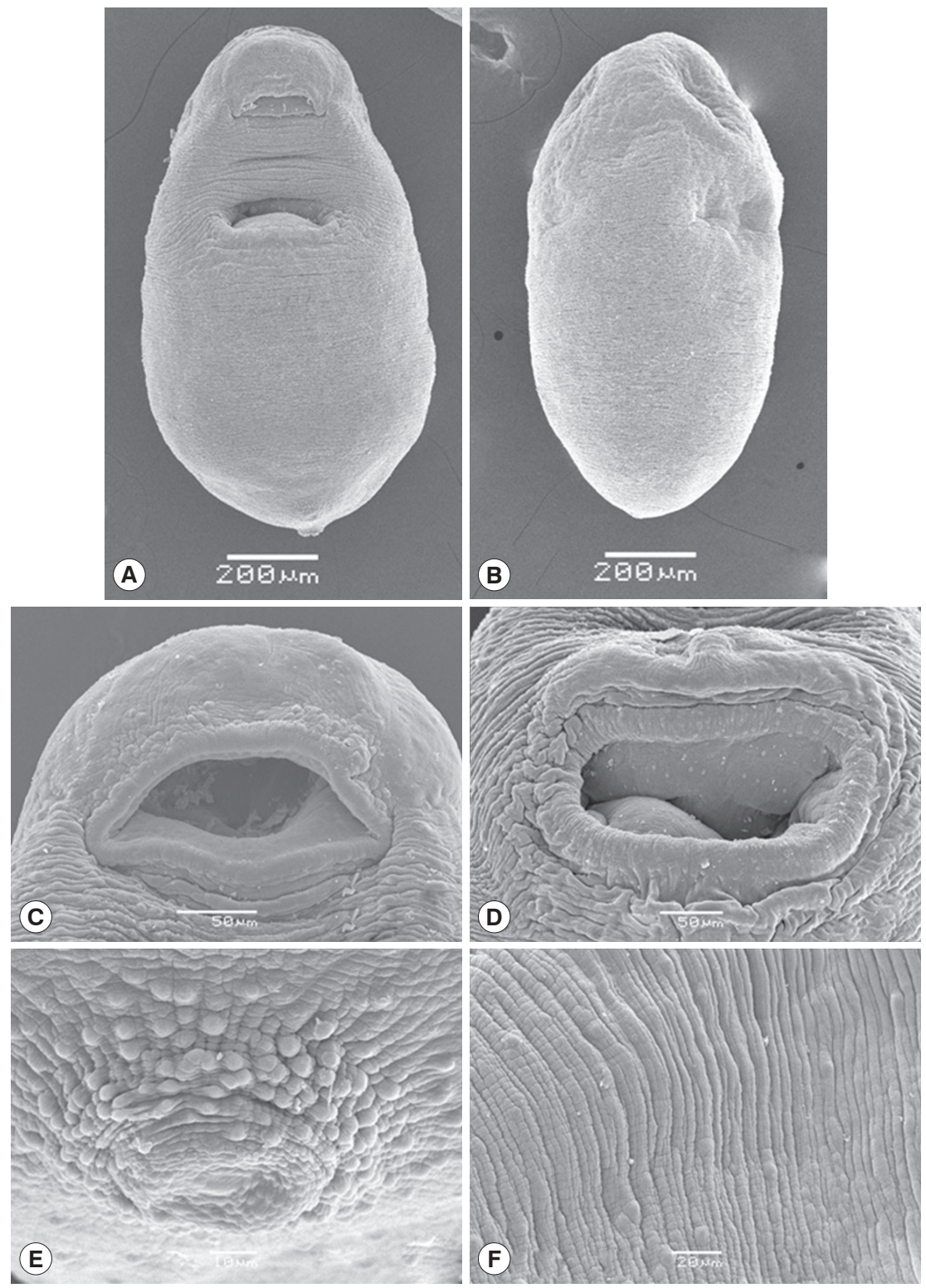

Fig. 3. Scanning electron microscopic photographs (SEM) of Thapariella anastomusa. (A) Ventral view of a whole fluke showing situation of the oral sucker, acetabulum, and excretory pore. (B) Dorsal view of a fluke showing the tegument fold without spines. (C, D) Oral and ventral suckers, well-developed and covered with sensory papillae. (E) Many sensory papillae around the excretory pore. $(F)$ The folds, grooves, and small knobs of the tegument.

\section{DISCUSSION}

This study is, to our knowledge, the first reported case of $T$. anastomusa metacercarial infections in $F$. martensi martensi and F. doliaris in Thailand. This trematode was first reported in viviparid snails in India [1], and a related species, Thapariella prudhoei, was later found in the Democratic Republic of Congo [2]. The report of metacercarial fauna of India has recorded that $T$. anastomusa metacercariae were discovered from the mouth cavity of Anastumus, having snail tissue. Next, the metacercariae of T. anastomusa were found encysted and free in snail Bellamya bengalensis. Moreover, the larvae of T. anastomusa have been redescribed that it is not encysted but found free in $B$. bengalensis [4]. The snail hosts (viviparid snails: F. martensi martensi and F. doliaris) have been reported as second intermediate host of Echinostoma revolutum, Echinostoma malayanum, and Echinostoma trivolvis in Vietnam and Thailand [5-8].

However, T. anastomusa had never been reported in Thai- 
land. The nearest genus to Thapariella is Amblosoma, which has been observed in Tennessee, USA [2]. These 2 genera are distinguished by differences in the uterus and vitellaria that occur in the fore and hind body [2]. Thapariella can be uniquely identified by their slightly diagonals, which are almost round in shape. The ovary is smaller than the testes, and the vitelline fields are very short and located in the hind body [9]. The morphology of $T$. anastomusa is very similar to T. prudhoei. $T$. anastomusa differs from T. prudhoei in vitellaria and testes located posterior-ventrally to the intestinal ceca, which vitellaria and testes of T. prudhoei crowed intercecally [2]. The definitive host of T. anastomusa is known to be several species of birds, such as aquatic birds [9]. While the larva of T. anastomusa has been found in viviparid snails, the location of sporocysts has yet to be determined $[2,9]$. The viviparid snails serve as the second intermediate host of T. anastomusa, as the same as Amblosoma pojmanskae, A. reelfooti, and A. exile $[2,10]$.

SEM analysis of T. anastomusa has been conducted and revealed its pyriform body with a concave ventral body, and well-developed oral and ventral suckers which allow the parasite to attach to the surface of hosts. The subterminal oral sucker is located in the anterior part of the body and scattered with sensory papillae. The ventral sucker is located at the anterior 2-thirds of the body. The subterminal excretory pore is located in the hind body and surrounded by sensory papillae. The folds and grooves are well-developed in all regions of the parasite surface, except in the anterior part of the dorsal surface, which is smooth. In addition, the surface area of all regions of the tegument is increased further by the presence of raised knobs. These suggested a high degree of absorptive ability in all regions of the tegument [11]. This study is, to our knowledge, the first report of T. anastomusa in Thailand examined by SEM, providing a detailed account of morphology.

Paddy fields are ubiquitous in Phitsanulok Province and across much of Thailand, providing a livelihood for an estimated 853,000 people. These fields are a suitable habitat for $F$. martensi martensi and F. doliaris, as well as the aquatic birds that prey on them and act as definitive hosts of T. anastomusa.

\section{ACKNOWLEDGMENTS}

Special thanks are extended to Parasitology Research Laboratory, Department of Biology, Faculty of Science, Chiang Mai
University for instrumental availability, to Environmental Science Research Center (ESRC), Chiang Mai University and Institute for Science and Technology Research for financial support. Thanks also to Nichar Gregory for reviewing an earlier draft of this manuscript.

\section{CONFLICT OF INTEREST}

The authors declare that there is no conflict of interest.

\section{REFERENCES}

1. Srivastava NN. On the morphology and systematic position of a new avian trematode Thapariella anastomusa n. g, n. sp., with a suggestion on the creation of a new family Thapariellidae. Indian J Helminthol 1953; 5: 101-108.

2. Goodman JD. Amblosoma reelfooti n. sp. (Trematoda: Brachylaimata Thapariellidae) from Viviparus intertextus in Tennessee and Thapariella prudhoei $\mathrm{n}$. sp. from Lanistes sp. in Zaire. Trans Am Microscop Soc 1990; 109: 319-324.

3. Brandt RAM. The non-marine aquatic mollusca of Thailand. Für Molluskenkunde 1974; 105: 1-423.

4. Panday KC, Agrawal N. Metacercarial Fauna of India. Kolkata, India. Zoological Survey of India. 2013, p 1-310.

5. Chai JY, Sohn WM, Na BK, Nguyen VD. Echinostoma revolutum: metacercariae in Filopaludina snails from Nam Dinh Province, Vietnam, and adults from experimental hamsters. Korean J Parasitol 2011; 49: 445-455.

6. Chantima K, Chai JY, Wongsawad C. Echinostoma revolutum: freshwater snails as the second intermediate hosts in Chiang Mai, Thailand. Korean J Parasitol 2013; 51: 183-189.

7. Noikong W, Wongsawad C. Epidemiology and molecular genotyping of echinostome metacercariae in Filopaludina snails in Lamphun Province, Thailand. Asian Pac J Trop Med 2014; 7: 26-29.

8. Noikong W, Wongsawad C, Chai JY, Saenphet S, Trudgett A. Molecular analysis of echinostome metacercariae from their second intermediate host found in a localised geographic region reveals genetic heterogeneity and possible cryptic speciation. PLoS Negl Trop Dis 2014; 8: e2778.

9. Gibson DI, Jones A, Bray RA. Keys to the Trematoda. Vol. 1. London, UK. CABI. 2002.

10. Font WF. Occurrence of Leucochloridiomorpha constantiae and Amblosoma pojmanskae metacercariae in the southeastern United States. Proc Helminthol Soc Wash 1984; 51: 166-168.

11. Panyarachun B, Sobhon P, Tinikul Y, Chotwiwatthanakun C, Anupunpisit V, Anuracpreeda P. Paramphistomum cervi: surface topography of the tegument of adult fluke. Exp Parasitol 2010; 125: 95-99. 